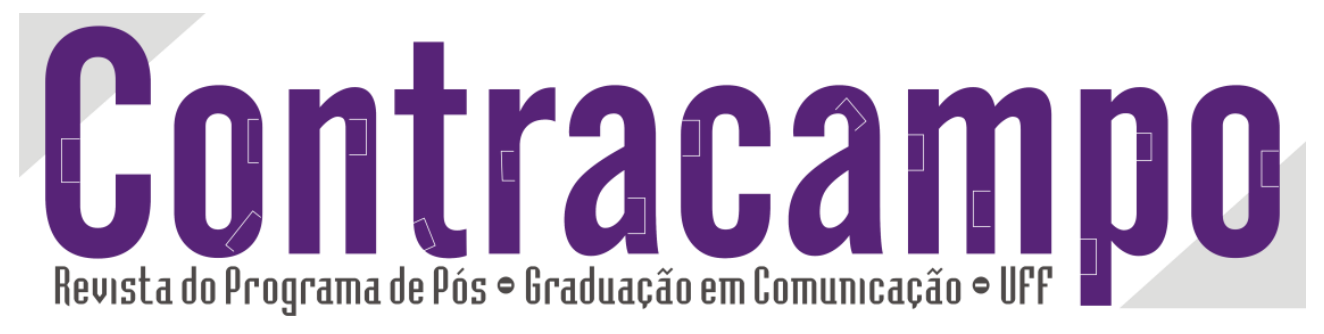

\title{
O interlocutor jornalístico: representações imaginárias do leitor do Estadão
}

\author{
The newspaper interlocutor: \\ Imaginary representation of the Estadão reader`s
}

Laura Storch

Isstorch@gmail.com

Jornalista, mestre em Comunicação e Informação pela Universidade Federal do Rio Grande do Sul, doutoranda pelo mesmo programa e instituição, e bolsista Capes.

Silvia Lisboa

lisboasilvia@gmail.com

Jornalista e mestre em Comunicação e informação pela Universidade Federal do Rio Grande do Sul.

Ao citar este artigo, utilize a seguinte referência bibliográfica

STORCH, Laura; LISBOA, Silvia. O interlocutor jornalístico: representações imaginárias do leitor do Estadão. In: Revista Contracampo, v. 24, n. 1, ed. julho, ano 2012. Niterói: Contracampo, 2012. Pags: 178-194.

Enviado em: 02 de fev. de 2012 Aceito em: 28 de mar. De 2012

\section{PPGCOM} UFF

\section{Edição 24/2012}

Temáticas diversas

Contracampo

Niterói (RJ), v. 24, n. 1, jul./2012.

e-ISSN 2238-2577 www.uff.br/contracampo

A Revista Contracampo é uma revista eletrônica do Programa de PósGraduação em Comunicação da Universidade Federal Fluminense e tem como objetivo contribuir para a reflexão crítica em torno do campo midiático, atuando como espaço de circulação da pesquisa e do pensamento acadêmico. 


\section{Resumo}

Neste trabalho, problematizamos o leitor como interlocutor no discurso jornalístico. Buscando mapear as representações imaginárias inscritas em sua relação com os jornais, partimos de uma análise discursiva de 550 comentários realizados pelos leitores na versão online de $\mathrm{O}$ Estado de $\mathrm{S}$. Paulo. Ao falar com o jornal, o leitor assume certo posicionamento, socialmente reconhecido na constituição do contrato de comunicação estabelecido com o veículo. Propomos compreender esses movimentos de posicionamento do leitor no jogo enunciativo a partir da construção de sua própria identidade, acionando noções como a de formações imaginárias em Pêcheux e a de pré-discurso em Paveau. Desta forma, procuramos contribuir para a compreensão das condições de leitura do discurso jornalístico.

Palavras-chave: jornalismo; leitor; formações imaginárias.

\section{Abstract}

This study is about the reader and his relation with journalism discourse. We search for the reader's own imaginary representations analyzing 550 reader's comments in the site of $\mathrm{O}$ Estado de $\mathrm{S}$. Paulo newspaper. In the relation with the newspaper, the reader assumes a position which is socially recognized in the communicative contract. We aim to comprehend what are these positions and how the reader constructs his own identity. This study uses the concepts of imaginary formations of Pêucheux and the notion of pre-discourse of Paveau. The article tries to contribute with the comprehension of readings conditions of journalism discourse.

Keywords: journalism; reader; imaginary formations. 
relação entre o jornalismo e a leitura pode ser observada a partir de diferentes filiações teóricas, de forma que nos parece importante, desde já, salientar que inscrevemos nossa discussão em uma perspectiva discursiva. Alguns conceitos fundamentais norteiam este trabalho ${ }^{1}$ : pensamos o jornalismo como um gênero de discurso (BENETTI, 2008a), inscrito em um contrato de comunicação (CHARAUDEAU, 2007) que estabelece, entre outras coisas, diferentes posições de sujeitos, "quem fala e para quem". Essas posições tácitas são estabelecidas e estabelecem os movimentos interacionais de autoria e leitura e se organizam a partir de representações sobre o que é o jornalismo e como ele se desenvolve enquanto discurso. Essas representações estão inseridas já na problematização das condições de produção e leitura do discurso, na discussão de formações imaginárias proposta por Pêcheux (1990).

Neste trabalho, de forma a observar a operacionalidade desses conceitos, buscamos mapear os movimentos imaginários de representação de si e do outro a partir das marcas discursivas do posicionamento dos leitores do jornal O Estado de S. Paulo em comentários feitos no site do veículo.

\section{Leitura e discurso jornalístico}

Nossa discussão sobre leitor começa bem antes da observação de suas manifestações em comentários online. Inicia-se pelo processo de produção do discurso jornalístico. O discurso tem como pressuposto a relação entre sujeitos sóciohistoricamente situados, "o discurso não está no texto, e sim na prática discursiva exercida entre o enunciador e o leitor" (BENETTI; HAGEN, 2010: 124). Já na escrita o leitor está presente, como parte das condições de produção do discurso. Mesmo que de forma implícita, o jornalista sempre imagina o outro com quem busca se comunicar. 
Essa figura imaginada é o que a teoria do discurso chama de leitor imaginado ${ }^{2}$, uma figura conceitual com a qual os sujeitos do discurso travarão contato. Pêcheux (1990) nos propõe pensar essas posições de sujeitos a partir do que define como formações imaginárias, que designam a imagem que os sujeitos fazem de seu próprio lugar e do lugar do outro no processo discursivo.

[...] o sujeito que fala tem dois horizontes imaginários ao longo dos quais se desloca no processo enunciativo, refletindo sobre si e sobre seu interlocutor. Pergunta-se "quem sou eu para lhe falar assim?" e pergunta-se "quem é ele para que eu lhe fale assim?". Em contrapartida, o interlocutor lida com outros dois horizontes sobre si mesmo e sobre quem lhe fala, perguntando-se "quem sou eu para que ele me fale assim?" e "quem é ele para que me fale assim? (BENETTI, 2008b: 42).

Ao dizer, o jornalista assume uma posição em determinada formação social e é a partir desse lugar que antecipa representações do outro. Importa salientar aqui que o outro a quem o jornalista imagina não é unicamente o leitor do jornal, mas existem diversos sujeitos que contribuem para a idéia final de um leitor imaginado: as expectativas do jornalista envolvem, por exemplo, suas fontes, o editor, o veículo, os colegas de trabalho, entre outros.

Da mesma forma, quando o leitor abre o jornal, ele precisa negociar espaço de significação com o leitor imaginado ali já inscrito e, para tanto, também mobiliza representações prévias sobre si mesmo, sobre o jornal, o jornalismo e etc. Não é necessário que o leitor empírico ocupe concretamente o papel proposto pelo leitor imaginado, o que importa nessa elaboração teórica é que "os dois sujeitos envolvidos no processo possam compreender a posição de sujeito do outro, além da sua própria" (BENETTI, 2008b: 19).

Essa dinâmica de expectativas se organiza a partir do que Charaudeau (2007) chama de "contrato de comunicação", que pressupõe, por parte do leitor, o

\footnotetext{
${ }^{2}$ A figura conceitual do leitor imaginado aparece com diferentes denominações. Na teoria do discurso, por exemplo, figura como o "leitor virtual" proposto por Orlandi (2008). Outras vertentes teóricas, como a teoria literária, também se preocupam com essa figura, que aparece ora como "leitor visado", ora como "leitor implícito", "leitor modelo" ou "arquileitor" (MOUILLAUD, 1997). Cada uma dessas formulações apresenta diferenças conceituais específicas, ainda que todos se refiram à discussão do leitor implícito no texto ficcional.
} 
reconhecimento do discurso jornalístico e suas particularidades, desde as rotinas profissionais até as práticas de leitura.

O contrato de comunicação assenta-se sobre a compreensão dos elementos que constituem um quadro de referência, a moldura onde o discurso acontecerá. Se os sujeitos participantes do processo discursivo não reconhecem estes elementos, o discurso fica comprometido em sua inteligibilidade, eficácia e legitimação (BENETTI, 2008b: 39).

É, portanto, na leitura que se concretiza a possibilidade discursiva do jornalismo. Ao considerarmos a leitura como negociação de sentidos, entendemos que entre o texto pensado pelo autor e o texto lido pelo leitor há um processo de significação, que é aberto, mas não administrado: autor e leitor estão, cada qual, inseridos em determinações que são anteriores (da memória, do interdiscurso) e exteriores (históricas, culturais, sociais) e, podemos dizer, o lugar social dos interlocutores é parte constitutiva do processo de significação. Assim, todo texto tem uma história, e toda leitura tem uma historicidade própria - e ambas estão inseridas em uma dinâmica simultaneamente individual e coletiva.

Nosso objetivo neste trabalho é mapear elementos que nos permitam compreender um pouco melhor qual é este lugar social e histórico do leitor do jornalismo contemporâneo. Nos propomos a fazer isso a partir da observação de um caso que mobilizou reflexão profunda sobre a função social da prática. Antes, porém, é necessário fazer um breve percurso teórico que nos ajudará a situar como os sentidos atribuídos pelo leitor ao jornalismo, a si mesmo e a este contrato de comunicação, que os une em um processo de significações, fazem parte de um imaginário social mais amplo, de onde nascem as representações de si (eu, o leitor) e do outro (ele, o jornalismo).

Imaginário e produção de sentido

O imaginário é, para Ruiz (2003), a força criativa do "sem fundo humano" e alimenta as representações do mundo e da realidade. Mas o imaginário não pode ser cristalizado em representações, e essas não dão conta de explicar ou anunciar o 
imaginário. Ainda que momentaneamente estáticas, apenas renovam o sentido do mundo, submetidas ao fluxo transformador e criativo do imaginário: são ressignificadas continuamente, estão abertas, são móveis, flexíveis, mutantes.

Essa perspectiva se cerca de outro elemento - que aqui precisa ser considerado a linguagem. Se "nada humano existe além da linguagem" (RUIZ, 2003: 191), é através dela que o homem constrói as representações, simbolizações do mundo natural e da realidade. Desta forma, Ruiz (2003) debate um panorama em que a linguagem se conforma em uma dupla condição: de criatura e criadora. Ela pode ser considerada o resultado de um processo de "domesticação" da representação, instada pelo imaginário, mas é fator moderador (ainda que não definidor) do homem, porque precede a subjetividade:

[...] o sujeito, para poder constituir-se como tal, deve inserir-se num mundo cultural configurado simbolicamente por uma língua. É dentro dessa língua que tecerá sua identidade singular de sujeito histórico. A língua adquire, pois, o poder de objetivar, socializar os sujeitos históricos. É na linguagem socializada, língua, que somos, nos movemos e existimos (RUIZ, 2003: 194).

A representação só pode existir na forma de linguagem, que se apresenta como recriação simbólica e estará sempre impregnada de significação. Essa perspectiva, que salienta a impossibilidade de definição de um sentido estático para a representação, vai se aproximar da discussão bakhtiniana, que entende que os sentidos são produzidos em situações de atividade de linguagem, no uso das línguas como intermediadoras nas relações cotidianas. Como destaca Cereja, "seus elementos, como fruto de uma convenção, podem ser utilizados em diferentes enunciações com as mesmas indicações de sentido" (2008: 202).

Como Bakhtin (2010), Ruiz (2003) também está interessado em algo mais do que o sentido denotativo da linguagem e entende que a expansão da experiência simbólica se realiza em um movimento anterior, na representação. No pensamento bakhtiniano, essa anterioridade se configura no discurso e no movimento da alteridade, no "dialogismo" (BAKHTIN, 2010) - condição observada por Ruiz ao assumir que a palavra proferida não é um objeto, mas uma alteridade com a qual se confronta, de modo que os sentidos podem, então, ser entendidos como momentâneos. 
Aqui nos parece pertinente recuperar a discussão de Paveau (2007) sobre os prédiscursos. A autora francesa organiza uma importante relação entre o paradigma da cognição social e os debates centrados no discurso, buscando discutir os quadros prévios da produção discursiva: as formas ou representações que se configuram antes da transposição em discurso, manifestas em saberes compartilhados, conhecimentos enciclopédicos, postulados silenciosos, estereótipos. Para Paveau (2007), o discurso está sempre articulado com dados exteriores que o impedem de ser um simples interior fechado em si mesmo; e dados anteriores, que são de ordem perceptiva e representacional, mas pré-configurados pela dimensão linguística.

Meu ponto de partida considera que existe uma co-elaboração ao mesmo tempo entre as produções discursivo-cognitivas individuais de cada um (meus quadros prévios e minha competência discursiva só podem ser ativadas em colaboração com as suas) e entre as produções individuais e sociais (meu comportamento individual está impregnado de social e, correlativamente, os fenômenos coletivos de uma sociedade estão marcados pelas inovações individuais) (PAVEAU, 2007: 320).

O debate sobre esses quadros pré-discursivos é amparado na recuperação de duas noções advindas de Pêcheux: a de "condições de produção dos discursos", por nós já esboçada na primeira parte deste trabalho; e na idéia de um "discurso prévio". Para a autora, o interesse de Pêcheux e de seus colegas pelo debate do discurso prévio e dos pré-constructos $^{3}$ demonstra uma configuração conceitual com clara preocupação com as determinações inconscientes do discurso. Partindo de uma proposta sócio-cognitiva,

[...] os pré-discursos podem ser vistos como operadores na negociação do compartilhamento, da transmissão e da circulação do sentido nos grupos sociais [...] um conjunto de quadros pré-discursivos coletivos que têm um papel instrucional na produção e interpretação do sentido em discurso. São quadros de saber, de crença e de prática que não estão disponíveis apenas no espírito dos indivíduos e na cultura dos grupos [...], mas estão distribuídos, no sentido cognitivo desse termo,

\footnotetext{
${ }^{3}$ A noção de pré-constructo aparece em uma reflexão conjunta de Culioli e Pêcheux, nos anos 1970, e "diz respeito ao inassertado (nível em que as origens do discurso foram esquecidas), na medida em que corresponde a uma sequência encaixada em uma outra de modo invisível, com um efeito de evidência prévia" (PAVEAU, 2007, p. 316).
} 
nos ambientes materiais da produção discursiva [...] (PAVEAU, 2007: 318).

A grande contribuição da autora para a discussão do imaginário e da linguagem, como vínhamos traçando, é a inter-relação que a idéia de pré-discurso permite entre noções abstratas como imaginário e cultura em relação à linguagem (a partir de conceitos como a intersubjetividade, o compartilhamento e a transmissão), e a possibilidade de observação desses movimentos em circulação nos discursos. Dito de outra forma, entender como os pré-discursos se difundem entre os diversos sujeitos nas formações imaginárias.

Neste trabalho, nos importa analisar as inscrições imaginárias do leitor do jornalismo. Ao ler um jornal, o leitor mobiliza suas representações acerca do jornalismo e sobre o seu papel na construção do discurso jornalístico, situadas dentro do panorama dos quadros pré-discursivos a que Paveau se refere. As representações sobre certo "jornalismo ideal" contribuem para a configuração do que os estudos do discurso chamam de ethos prévio ou ethos pré-discursivo ${ }^{4}$. Antes de ler um jornal, o leitor já tem uma imagem preexistente deste locutor (do jornalismo em geral, ou do jornalista, em particular). É ao considerarmos as implicações desse conceito que podemos buscar compreender qual a imagem prévia que o leitor tem do jornalismo, da sua relação com a prática e de que forma ele se enxerga - ou não - no discurso jornalístico.

Para Maingueneau, a noção de ethos permite refletir sobre o "processo mais geral da adesão dos sujeitos a certa posição discursiva" (2005: 71). O texto jornalístico pertence, como observa Benetti (2008), a um gênero de discurso socialmente conhecido, o que por si induz expectativas em relação ao ethos. São essas expectativas que formam o ethos prévio e são mobilizadas cada vez que o leitor trava contato com um texto jornalístico. O que nos interessa aqui, porém, não é a representação que o leitor tem do jornalismo, mas como ele se posiciona como interlocutor do jornal, de que modo ele próprio constrói seu ethos, entendido como essa posição discursiva assumida dentro de um contrato de comunicação. Através da compreensão do seu ethos, será

\footnotetext{
${ }^{4}$ Maingueneau (2005) chama de ethos pré-discursivo, enquanto Amossy (2005) e Haddad (2005) usam o termo ethos prévio. O termo ethos se refere à construção de uma imagem de si que os antigos cunharam para designar o sucesso oratório.
} 
possível mapear os movimentos imaginários de representação de si e do outro, realizados pelo leitor.

\section{Mapeando as marcas do leitor do Estadão}

Propomos analisar as marcas discursivas do leitor empírico na dinâmica das formações imaginárias (quem sou eu para que me fale assim?), a partir de um exemplo empírico: as manifestações de leitores no ambiente de comentários do editorial " $\mathrm{O}$ mal a evitar", publicado na página online do jornal $\mathrm{O}$ Estado de S. Paulo (www.estadao.com.br $)^{5}$. Veiculado uma semana antes das eleições presidenciais brasileiras, em 25 de setembro de 2010, o editorial explicita o apoio do jornal ao candidato José Serra (PSDB) e faz duras críticas ao governo do então presidente Luiz Inácio Lula da Silva (PT). "O mal a evitar" seria a continuidade da chamada "Era Lula" em caso de vitória da candidata petista Dilma Rousseff.

A publicação do editorial foi amplamente comentada pelos leitores do jornal, atingindo um total de 2.604 intervenções apenas nos dois primeiros dias de circulação ${ }^{6}$. Uma análise preliminar deste material nos permitiu estabelecer a redução do corpus de comentários para 550, de modo que foram excluídos todos os comentários que não faziam referência ao jornal ou ao jornalismo, de forma mais ampla ${ }^{7}$. É possível observar um número considerável de intervenções de leitores que manifestaram sua opinião sobre a postura editorial do veículo e teceram comentários sobre o seu envolvimento com a história do jornal, por exemplo. Não interessam, em nossa análise, as opiniões ou julgamento sobre o conteúdo do editorial em si. Ao contrário, nos interessa nas manifestações a possibilidade de observar as marcas do leitor em sua relação com o jornal - os lugares discursivos determinados na estrutura dessa formação social.

\footnotetext{
${ }^{5}$ As referências, nesse trabalho, a versão online do jornal O Estado de S. Paulo correspondem ao conteúdo disponibilizado em www.estadao.com.br e não devem ser confundidas com a versão digital do jornal impresso, conhecida como Estadão Digital, disponível em www.digital.estadao.com.br, onde o acesso ao conteúdo é restrito a assinantes.

${ }^{6}$ Analisamos os dias 25 e 26 de setembro de 2010, datas das publicações do editorial no site e no impresso, respectivamente.

${ }^{7}$ Entre os comentários excluídos figuram, por exemplo, manifestações sobre o sistema de postagem do site, interações diretas entre usuários que não se relacionavam ao tema do editorial, spams, entre outros.
} 
É importante salientar que essas marcas aparecem na relação entre sujeitos, que ocupam posições sociais, e um referente, o contexto ou situação comunicacional. Na análise dos comentários ao editorial, pudemos observar duas ordens distintas de marcas discursivas que podem nos fornecer pistas sobre a posição do leitor na relação imaginária com o jornal: a primeira salienta como o leitor se apresenta a partir de quem ele é na relação com o jornal ou na sociedade e a partir das relações cotidianas e emocionais que ele estabelece com o objeto do jornal; e a segunda, mais complexa, se apresenta na contraposição a outro em quem ele não se reconhece. Buscaremos desenvolver essas duas ordens discursivas a seguir ${ }^{8}$.

$\mathrm{Na}$ interação com o editorial do www.estadao.com.br, o comentarista se posiciona para falar com o jornal a partir do que considera seus lugares mais legítimos: o de assinante e o de Leitor ${ }^{9}$. É como assinante que ele se sente à vontade para aprovar ou reprovar as atitudes e opiniões do jornal - é importante notar, mais uma vez, que não nos interessa a opinião do leitor sobre o conteúdo do editorial e que opiniões divergentes são enunciadas de uma mesma posição de sujeito.

Acabo de rasgar a minha assinatura deste EX qualificado jornal. NeM é pela postura de apoiar um candidato... pasmem ninguém sabia disso Estadão :S. Mas quero um jornal IMparcial.

È por atitudes como esta, pela responsabilidade e pela coragem, que leio e assino o ESTADÃO há mais de 3 décadas. PARABENS!

Quem compra jornal na banca, não quer saber se é do partido A ou do partido B. É mesmo que comprar jornal de sindicato.

\footnotetext{
${ }^{8}$ Os exemplos de manifestações dos leitores apresentados neste trabalho correspondem ao que, no discurso, é chamado de "sequências discursivas": "o trecho que arbitrariamente recortamos para análise e depois utilizamos no relato de pesquisa" (BENETTI, 2007, p. 112). Os comentários foram reproduzidos fielmente, sem nossa interferência na correção de eventuais erros de ortografia ou digitação, para não alterar as sequências discursivas. Os grifos, porém, são nossos. A ausência de informações de identificação dos usuários (nome ou pseudônimo, por exemplo) também é uma escolha nossa, teórica e metodologicamente justificada pela observação de que esses dados não oferecem nenhuma contribuição à análise empírica, que busca observar a conformação de posições de sujeito inscritas nas manifestações dos leitores.

${ }^{9}$ Optamos pela grafia "leitor" com letras minúsculas para nos referir à concepção mais ampla da palavra, na leitura. A grafia "Leitor", com a primeira letra em maiúscula, servirá para referenciar a posição do sujeito em relação ao jornal, seu estatuto na dinâmica do contrato de comunicação.
} 
Retomo a assinatura do jornal (agora pela via digital) como forma de apoiar seu trabalho e juntar minha voz à sua.

Bom. Primeiro. O Estadão perdeu um leitor e consumidor de seus jornais. Porque acho que o dever de informar deve ser totalmente imparcial, o direito de informação do brasileiro deve estar acima de interesses partidários.

Mas não é apenas como assinante do veículo que o comentarista se posiciona. A sua história como Leitor do jornal é elemento fundamental de sua representação no jogo enunciativo - o leitor entende fazer parte da dinâmica comunicacional, sabe o que é esperado dele e o que ele deve esperar do jornal. O comentarista que assume essa posição também opina, valida ou recusa o conteúdo do editorial e a postura do jornal, questiona a legitimidade do lugar institucional que o jornal ocupa (quem é ele pra que me fale assim?), e só faz isso porque assume sua posição no jogo das formações imaginárias, sua posição de Leitor (quem sou eu para que ele me fale assim?).

(...) o jornal é um meio de comunicação de masa, e não de escolha de A ou $\mathrm{B}$, pois são leitores de ambas tendencias politicas, este é o repudio e a decepção de um leitor assiduo deste jornal por mais de 10 anos.........

Somente os ingenuos ou menos avisados precisariam de Editoriais diretos. Quem acompanha o jornal O Estado, como eu, há mais de 50 anos, sempre me orgulhei e invejei seus Editoriais.

Continuarei lendo o Estadão, pois sei que "depois que o carnaval passar" o bom censo volta. Afinal aí tá cheio de bons profissionais.....

Essa relação com o jornal se torna mais complexa ao considerarmos que os vínculos entre jornal e leitor podem ir muito além do conteúdo impresso ao qual ele tem acesso todo dia. A construção de laços de familiaridade e fidelização com um jornal passa, muitas vezes, pelo atrelamento do jornal em ritos cotidianos (a rotina da compra na banca, os costumes próprios de leitura), no imaginário (também da ficção) sobre o jornalismo, ou mesmo por um envolvimento emocional muito pessoal, às vezes ligado à história de vida ou da família. Esses vínculos exercem um papel preponderante na constituição das posições de sujeito no contrato de comunicação.

Parei hoje, num domingo chuvoso, em frente a uma banca de jornal para um simples exercício - o qual todos os homens e mulheres de boa 
vontade deveriam fazer, juntamente com o eterno pão com manteiga e café preto - que é o de ler as principais manchetes de jornal. Não que eu tivesse a intenção de comprar mas, esse momento acaba por fazer parte de uma rotina maior daquela que estamos acostumados a dispensar a outros que não nós mesmos. Sem a intenção de parecer panfletário ou influenciar opiniões, quem me dera, me achei na obrigação de distribuir a opinião do jornal Estado de São Paulo publicada nesta manhã - a toda a minha lista de contatos.

Abracem-se com a amiguinha Veja e feliz queda no abismo daquele que já foi o melhor jornal do país, e que eu lia religiosamente nas manhãs de domingo.

Que papelão, héin, senhores! Há seis meses cancelei minha assinatura do Estadão por causa da imparcialidade disfarçada de isenção. E olha que já fui premiado, em 2006, com por este jornal, no concurso de contos para a Copa do Mundo daquele ano. Estadão: volte a ser $o$ jornal que eu, quando era criança, ajudei meu pai a entregar, ele um humilde Joao entregador de jornal na Catumbi, depois na Vila Mariana e por último nos Jardins. Que saudade daquele jornal conservador mas sincero NA HORA CERTA, não depois do leite derramado.

quando a 43 anos atrás cheguei a SP no sábado no domingo comprei $o$ Estadão e alí encontrei um jornal que lutava contra a ditadura ainda light, agora em 2010 acossado pelas dívidas e toda sorte de pressão, sinto que pode ter o mesmo destino do JB.

O leitor assume esse vínculo subjetivo como um valor imaginário que o coloca em posição de interlocutor do jornal. De forma um pouco semelhante, um terceiro movimento de posicionamento do leitor em sua relação com o Estadão se dá a partir da indicação de sua posição social na comunidade - quem ele é, o que ele faz -, que o permite assumir uma posição legitima para interpelar o jornal frente a si mesmo e aos outros. Aqui não é apenas a condição de Leitor do jornal, mas a condição de qualificação desse Leitor - assumir-se a partir de um de seus papéis sociais, não mais um leitor genérico, mas como um leitor que carrega relações com outros leitores e com o próprio jornal. Os exemplos nos ajudarão a compreender a posição de leitor:

Um grande jornal só poderia ter uma grande coragem: dá orgulho ser jornalista ao ler o editorial de hoje. Nem tudo está perdido neste País. 
Parabens ao Estadão pela coragem e iniciativa. Tenho orgulho de fazer parte dessa grande familia e de falar "sim, trabalho no estadão"

Eu mesmo, tanto quando presidente da APEOESP como da CUT já fui caluniado e agredido por essa mídia. Sendo que me foi dado como direito de resposta uma "cartinha" no painel do leitor. Outros nem isso.

Sou educador e fiquei enojado quando a grande mídia paulista tentou confundir deliberadamente o movimento de luta dos professores por dignidade com os interesses políticos de centrais sindicais ou partidos.

Assim, ao se anunciar como jornalista, funcionário da empresa, fonte, militante político ou a partir de sua condição profissional, entre outros, o leitor busca incluir na sua argumentação um valor de interlocução com o jornal e com os outros leitores mobiliza pré-discursos e representações sobre certa posição social compartilhada e busca, no reconhecimento dos valores deste papel social, sua posição de interlocução. Essa referência ajuda a exemplificar a idéia do leitor imaginado do jornalismo como uma figura múltipla, onde diferentes sujeitos compartilham para a construção de um interlocutor virtual.

Uma segunda ordem de marcas discursivas pode ser observada a partir de uma idéia de outro: outro em relação ao jornal ou em relação aos leitores do jornal. Benetti lembra, debatendo o contrato de comunicação em Charaudeau, que "a partir da finalidade e do propósito do jornalismo, controem-se as identidades do jornalista e do leitor, bem como dos demais sujeitos na situação de comunicação" (2008b: 40-41). Aqui, ao qualificar o outro, o leitor elabora identificações de si. Ao indicar quem ele não é, o leitor assume a posição de quem ele é na relação com o jornal.

Essa forma de se posicionar pode aparecer como oposição (você é isso, então eu sou aquilo) ou identificação (você é isso, por isso sou aquilo), e aparece, em nossa análise, majoritariamente na oposição contextual entre o "brasileiro" e o "paulista".

O editor se refere de forma preconceituosa com os brasileiros. Segundo ele os brasileiros tem uma "mentalidade" que se deixa hipnotizar. São estas frase de "brasileiros como o editor" fruto de preconceito. Afinal sempre defenderam que são diferentes dos brasileiros. 
Em resumo nos chamam nos milhões de brasileiros de pessoas que precisam DELES, para que saibamos votar. Ora pois, QUE PAÍS e este?

Ora, vcs tem um grande problema, que é substimar a inteligência do povo brasileiro. A grande midia que apoiou golpes militares em nosso país devia ter vergonha em continuar com esse discurso tentando confundir a opinião pública. Me dá vergonha de ser paulista!

Entretanto, fico pasmo e acredito que qq pessoa que tenha o mínimo de discernimento ficaria ao verificar a falta de escrúpulo dessa mídia provinciana infelizmente paulistana que por trás disso não está preocupada com o País mas sim o seu 'status quo. Pensam que o Brasil é Sao Paulo.

Talvez seja importante ressaltar a importância que, neste contexto, a idéia de identificação assume: o leitor associa certo ethos ao jornal, se filia a ele ou o acusa para justificar sua opinião. O jornal O Estado de S. Paulo é um jornal de circulação nacional, criado e sediado no estado de São Paulo. Considerando o contexto, uma questão nacional por excelência - eleições presidenciais -, o posicionamento do leitor ativa as noções que ele reconhece como sendo o ethos do jornal, construídas historicamente, em sua relação com o mundo e com o veículo. Outro posicionamento manifesto pelo leitor, vinculado ao contexto, e que aparece de forma minoritária em nossa análise, se dá na figura do "eleitor".

Vocês não pensaram nos milhões de eleitores que não apoiam nem um dos dois partidos, ou será que só tem os dois?!

Não concordo que para apoiar um candidato não precisa desqualificar o outro, é falta de respeito com quem vota em Dilma Rousseff. Dilma representa um projeto de sucesso para o país...31 milhões de brasileiros que entraram para a classe média ( inclusive eu ), 14 milhões de empregos gerados, 700 mil jovens pobres na universidade (creio que está aí o medo deste jornal ).....

Essas manifestações também salientam algumas idéias socialmente compartilhadas sobre o jornalismo em relação ao interesse público, e remetem a uma posição imaginária, assumida pelo leitor, como "povo", "país" ou "sociedade". O leitor se assume em uma categoria mais ampla de representação de forma a suportar seus 
comentários e argumentar (positiva ou negativamente) a legitimidade e credibilidade do jornal, além de sua atuação a partir de noções consensuais acerca do jornalismo.

80\% DOS BRASILEIROS, SÃO IGNORANTES OS INTELIGENTES SÃO SÓ VOCES.E ESTA OLIGARQUIA, QUE SEMPRE SE BENEFICIARAM DA IGNORANCIA DOS BRASILEIROS.

E o pior é a imprensa querendo se dizer a voz do povo. Se está contraria a vontade da grande maioria e pensa diferente da grande maioria.... Pensando bem, temos a imprensa certa mas no país errado. O Brasil de verdade, infelizmente, é outro.

A Sociedade Brasileira, CONSTITUIDA EM SUA MAIORIA DE SERES INVISÍVEIS, com sua força e face renovada OS VENCERAM.

Parabéns Estadão. Sempre com uma postura responsável, ética, e acima de tudo corajosa. PARABÉNS ... O BRASIL AGRADECE!

As categorias representadas nessa análise buscam salientar diferentes movimentos discursivos de posicionamento do leitor enquanto interlocutor do Estadão. Devemos considerar, pela inscrição na perspectiva do discurso, que a leitura é um processo inscrito simultaneamente em uma relação que considera o individual (as competências de leitura, uma biografia interdiscursiva) e o coletivo (o imaginário, a cultura, o social - os quadros pré-discursivos). Dessa forma, a leitura sempre será negociação de sentidos possíveis e, ainda que não sejam generalizáveis, os posicionamentos observados aqui nos auxiliam a compreender, de forma mais ampla mesmo que momentaneamente - as complexas relações que o leitor estabelece com o jornal na tomada de posição na dinâmica de comunicação.

\section{Considerações Finais}

O contrato de comunicação jornalístico pressupõe a interação de cinco elementos essenciais: "quem diz e para quem", "para quê se diz”, “o que se diz”, “em que condições se diz" e "como se diz". Esses elementos são indissociáveis no processo discursivo, mas cada um coloca desafios teóricos importantes na busca da compreensão de como o jornalismo se constitui como gênero discursivo particular. Nos propomos, 
neste texto, a problematizar a primeira condição, de identidade (quem diz e para quem?), sobre um ponto de vista específico nos estudos de jornalismo, o do leitor.

$\mathrm{Na}$ ininterrupta teia de significações do processo discursivo, jornalista e leitor assumem posições de interlocução onde mobilizam representações imaginárias de si e do outro. Por meio de uma análise empírica, buscamos compreender que imagens o leitor aciona sobre si no movimento de interlocução com o jornal. A análise nos permitiu observar que o leitor ocupa sua condição de interlocutor reconhecendo seu papel no jogo discursivo, e tanto explora sua condição de financiador do veículo, como "assinante", como se vale de posições sociais mais amplas e também reconhecidas, como sugere a noção de "povo" ou "eleitor". Além disso, mais do que elementos formais, laços subjetivos se destacam como norteadores da relação entre veículo e leitor, que recorre à sua história e aos vínculos emocionais que mantêm com o jornal para firmar sua posição no jogo enunciativo e construir sua própria identidade, às vezes em clara oposição àquela imaginada pelo jornalismo.

Nossa intenção neste trabalho era a de problematizar a leitura na dinâmica discursiva do jornalismo. A observação do leitor em suas manifestações aos veículos abre um campo profícuo de investigação sobre sua relação com os jornais, de forma mais ampla. O detalhamento de como se dão os movimentos de posicionamento do leitor ajuda a dimensionar, de forma mais ampla, o lugar do jornalismo enquanto mediador da realidade e produtor de sentidos sobre o mundo e o homem e as relações comunicativas estabelecidas a partir desse ator comunicacional ainda pouco conhecido pelo campo de pesquisa em Jornalismo.

\section{Referências bibliográficas}

AMOSSY, Ruth (org.). Imagens de si no discurso: a construção do ethos. São Paulo: Contexto, 2005.

BAKHTIN, Mikhail. Marxismo e Filosofia da Linguagem: problemas fundamentais do método sociológico da linguagem. $14^{\circ}$ Ed. São Paulo: Hucitec, 2010.

BENETTI, Marcia. Análise do Discurso em Jornalismo: estudo de vozes e sentidos. In: LAGO, Claudia, BENETTI, Marcia. Metodologia de Pesquisa em Jornalismo. Petrópolis: Vozes, 2007.

2008a.

O jornalismo como gênero discursivo. Galáxia. n. 15, junho. São Paulo: PUCSP, 
Blogs jornalísticos e formações imaginárias. Eco-Pós. Vol.11, n. 2. Rio de Janeiro: UFRJ, 2008b.

; HAGEN, Sean. Jornalismo e imagem de si: o discurso institucional das revistas semanais. Estudos em Jornalismo e Mídia. Ano VII, n. 1, janeiro-julho. Florianópolis: UFSC, 2010.

CEREJA, William. Significação e tema. In: BRAIT, Beth (org.). Bakhtin: conceitos-chave. São Paulo: Contexto, 2008.

CHARAUDEAU, Patrick. Discurso das mídias. São Paulo: Contexto, 2007.

HADDAD, Galit. Ethos prévio e ethos discursivo: o exemplo de Romain Rolland. In: AMOSSY, Ruth (org.). Imagens de si no discurso: a construção do ethos. São Paulo: Contexto, 2005.

MAINGUENEAU, Dominic. Ethos, cenografia e incorporação. In: AMOSSY, Ruth (org.). Imagens de si no discurso: a construção do ethos. São Paulo: Contexto, 2005.

MOUILLAUD, Maurice. O jornal: da forma ao sentido. Brasília: Paralelo 15, 1997.

ORLANDI, Eni. Discurso e Leitura. $8^{\circ}$ Ed. São Paulo: Cortez, 2008.

PAVEAU, Marie-Anne. Palavras anteriores: os pré-discursos entre memória e cognição. Filologia e Língua Portuguesa, n. 9. São Paulo: USP, 2007.

PÊCHEUX, Michel. Análise Automática do Discurso (AAD-69). In: GADET, F.; HAK, T (orgs.). Por uma análise automática do discurso: uma introdução à Obra de Michel Pêcheux. Campinas: Unicamp, 1990.

RUIZ, Castor Bartolomé. Os paradoxos do imaginário. São Leopoldo: Unisinos, 2003.BERMAS, Jürgen. "Jürgen Habermas: Morality, Society and Ethics - an interview with Torben Hviid Nielsen", Acta Sociologica, n.33, v.2, 1990, pp.93-114. 